ISSN 1518-3483

Licenciado sob uma Licença Creative Commons

\title{
Os clássicos na formação docente: reflexões acerca do PNE (2014)
}

\author{
The classics in teacher formation: reflections \\ on the NEP (2014)
}

Terezinha Oliveira, Rafael Henrique Santin*

[a] Universidade Estadual de Maringá (UEM), Maringá, Paraná, Brasil.

\section{Resumo}

O artigo que apresentamos traz para o debate as metas do novo Plano Nacional de Educação (PNE), que tratam da formação de professores analisado à luz de dois clássicos do pensamento medieval,: João de Salsbury (século XII) e Boaventura de Bagnoregio (século XIII). Não pretendemos, com isso, afirmar que os escritos desses dois pensadores da Idade Média são capazes, por si, de nos fazer entender o PNE e influenciar diretamente o encaminhamento a ser dado para a educação no presente, como se o presente pudesse ser entendido a partir dos pressupostos do passado. Todavia, uma reflexão a partir de

* TO: Pós-doutora, e-mail: teleoliv@gmail.com

RHS: Mestre, e-mail: rafael.h.santin@gmail.com 
uma experiência do passado pode nos proporcionar importantes lições para compreendermos melhor o que significa educação de excelência. Para isso, partimos dos princípios teórico-metodológicos da História Social, que assevera ser o homem no tempo o objeto próprio da história como ciência.

Palavras-chave: História da Educação Medieval. Plano Nacional de Educação. João de Salsbury. Boaventura de Bagnoregio.

\section{Abstract}

The article that is now presented bring to the debate the goals of the new National Education Plan (NEP), dealing with teacher training, examined in the light of two classics of medieval thought, John Salsbury (XII century) and Bonaventure of Bagnoregio (thirteenth century ). We do not wish, therefore, to emphasize that the writings of these two thinkers from the Middle Ages are able, by themselves, to make us understand the NEP and directly influence the routing to be given to education in the present time, as if the present could be understood from the from the assumptions of the past. Indeed, our first intention is to bring important lessons to understand better what it means to be a teacher with a view to an education of excellence. For that, we use the theoretical and methodological principles of Social History, which asserts that the man in time is the very object of history as science.

Keywords: History of Medieval Education, National Education Plan, John of Salsbury, Bonaventure of Bagnoregio.

\section{Introdução}

O novo Plano Nacional de Educação (PNE), posto em prática no ano de 2014 por meio da lei $n^{0} 13.005$, é um documento fundamental para percebemos o modo como o Estado brasileiro vem lidando com a educação escolar. Dele emanam as diretrizes para a formulação das 
políticas públicas educacionais que, por sua vez, influenciam o modo como gestores e professores trabalham, ao menos no período de sua vigência, que é de dez anos. Essa influência se exerce, principalmente, por meio das 20 (vinte) metas a serem alcançadas até 2024, ano no qual teremos outro Plano Nacional que estabelecerá novas metas para os próximos 10 (dez) anos.

Em face disso, o nosso propósito é refletir sobre algumas dessas metas à luz dos ensinamentos de alguns pensadores medievais, partindo do pressuposto do qual a História da Educação Medieval pode nos fornecer lições para pensarmos a formação de crianças, jovens e adultos, bem como, sobre o papel daqueles, cuja função primordial é ensinar, os professores.

Assim, fica evidente que uma de nossas fontes principais é, justamente, a lei $n^{0} 13.005$ de 25 de junho de 2014, a qual estabelece o Plano Nacional de Educação, com vigência até 2024. Dentre os autores medievais que podem nos fornecer subsídios à reflexão sobre esse documento selecionamos os que consideramos pertinentes no presente, visto que, tratam essencialmente da formação de líderes, ou seja, daqueles os quais têm a responsabilidade pela condução da sociedade a partir da noção de bem-comum. Com efeito, Polycraticus, de João de Salsbury (1120-1180), e A perfeição da vida, de Boaventura de Bagnoregio (1221-1274), são obras que abordam o caráter da formação dos homens que deveriam se ocupar em assegurar o desenvolvimento das relações sociais citadinas.

Essa caracterização do objeto e das fontes para a elaboração do artigo nos conduz à consideração de nossa metodologia, assim como de um conceito, que nos é bastante caro, o de civilização.

Para a elaboração deste trabalho, partimos dos pressupostos teórico-metodológicos da História Social, segundo a qual o objeto da história é o homem, isto é, a ação humana no tempo. Marc Bloch (2001), historiador do século XX, em Apologia da história, ou O ofício de historiador, afirma que o estudioso da história deve assemelhar-se ao ogro da lenda, que está sempre onde sente o cheiro de carne humana. 
Além disso, assevera que o estudo da história nos permite verificar os elementos permanentes da humanidade. Isso é importante na medida em que direciona o trabalho do historiador para o estudo, não só dos processos de transformações individuais e coletivas por que passa a sociedade, mas também para a análise da essência humana. Dito de outro modo, daquilo que nos caracteriza como seres humanos.

Não é nossa intenção advogar que a história seja suficiente para a compreensão do homem, ou que ela, sozinha, é capaz de desvelar todas as características da humanidade. Com efeito, concordamos com Nietzsche, filósofo do século XIX, que escreveu, na Segunda consideração intempestiva, que a história nos permite "[...] entender a expressão 'foi', a senha através da qual a luta, o sofrimento e o enfado se aproximam do homem para lembrá-lo o que é no fundo sua existência - um imperfectum que nunca pode ser acabado" (NIETZSCHE, 2003, p. 8, grifo do autor). É nesse sentido que entendemos poder extrair, do estudo da história, lições relevantes para pensarmos sobre os homens, as relações sociais e, especialmente, o Plano Nacional de Educação.

O conhecimento da história, segundo as considerações de Nietzsche (2003), nos permite construir uma forma de pensar e agir com mais prudência e, em última instância, a unidade entre o pensar e o agir:

O hábito em um tal ser doméstico desordenado, tempestuoso e conflituoso torna-se paulatinamente uma segunda natureza, mesmo se estiver imediatamente fora de questão o fato de esta segunda natureza ser muito mais fraca, muito mais inquieta e em tudo menos saudável do que a primeira. Por fim, o homem moderno arrasta consigo por aí uma massa descomunal de pedras indigeríveis de saber que, então, como nos contos de fadas, podem ser às vezes ouvidas rolando ordenadamente no interior do corpo. Com estes solavancos denuncia-se a qualidade mais própria a este homem moderno: a estranha oposição entre uma interioridade à qual não corresponde nenhuma exterioridade e uma exterioridade à qual não corresponde nenhuma interioridade - uma oposição que os povos antigos não conheciam. O saber, consumido em excesso sem fome, sim, contra 
a necessidade, não atua mais como um agente transformador que impele para fora e permanece velado em um certo mundo interior caótico, que todo e qualquer homem moderno designa com um orgulho curioso como a 'interioridade' que lhe é característica. Diz-se então prontamente que se tem o conteúdo e só falta a forma; mas, em todo vivente, esta é uma oposição inteiramente impertinente (NIETZSCHE, 2003, p. 33).

As palavras de Nietzsche (2003) apontam para a relevância dos homens possuírem o conhecimento e, especialmente, saberem fazer uso dele. Nesse sentido, o conhecimento se efetiva em virtude da transformação que causa naquele que se apropria dele. Exatamente por isso, o autor destaca o fato do conhecimento não ser somente conteúdo ou forma, mas as duas condições.

Assim, a partir das considerações de Bloch (2001) e de Nietzsche (2003), procuramos nesse artigo, demonstrar alguns elementos que os clássicos nos fornecem para pensarmos a ação educativa no presente. Desse modo, não podemos considerar as metas do Plano Nacional de Educação para a formação dos professores sem termos explícito, antes, o que é ser professor, o que significa ensinar, aprender e transformar o outro. A nosso ver, é necessário esclarecer o propósito das metas do PNE a partir do projeto de educação e de sociedade que lhe é inerente.

Diante disso, também é preciso tratar do conceito de civilização adotado neste artigo, tal como mencionamos no início do texto. Para entendermos esse conceito, partimos das obras de outro autor do século XIX, o historiador francês François Guizot.

Guizot aborda o conceito de civilização na primeira lição da História da Civilização na Europa (1907), que reúne uma série de lições por ele ministradas como professor da Sorbonne (OLIVEIRA, 1997). Ele afirma que a civilização pode ser entendida a partir do desenvolvimento de seus dois pilares fundamentais: o indivíduo e as instituições. Isso significa que se retirarmos o indivíduo ou as instituições da 
'equação' e se esses elementos não se desenvolverem concomitantemente, não há civilização.

Para nós, a primeira intenção é tratar das metas do PNE para a formação dos professores, esse conceito é essencial, pois a escola é, atualmente, a instituição responsável pelo amadurecimento do indivíduo. Não nos esquecemos, evidentemente, de que a educação no Brasil é, de acordo com a Lei de Diretrizes e Bases da Educação Nacional (lei $n^{\circ} 9.394$ de 1996), uma responsabilidade da família e do Estado, mas consideramos que a instituição escolar é o locus, por excelência, de formação do indivíduo. Por conseguinte, os professores formam um dos principais grupos responsáveis pelo processo formativo. Desse modo, o sucesso e o fracasso da instituição escolar representam parte do fracasso e do sucesso do desenvolvimento dos indivíduos. Pensar a escola nessa perspectiva é preocupar-se, portanto, com os rumos da civilização brasileira.

\section{As metas do PNE (2014-2014) para a formação de professores e as lições de dois mestres medievais}

Em primeiro lugar, trazemos para o debate algumas considerações que julgamos pertinentes para o estudo das obras de João de Salsbury e de Boaventura de Bagnoregio, a fim de assinalarmos a importância das obras que elegemos para refletir sobre o PNE.

João de Salsbury nasceu em Salsbury, região que atualmente conhecemos como Inglaterra, e morreu em Chartres. Durante sua formação, esteve em contato com eminentes professores do século XII, considerados vanguardistas do movimento, chamado por alguns pesquisadores da Idade Média, como Jacques Le Goff (2010) e Etienne Gilson (2005), de Renascimento do século XII. Ele estudou, inclusive, na cidade que era então considerada o centro cultural do Ocidente, Paris, e foi aluno de Gilberto de Poitiers, Guilherme de Conches e de Pedro Abelardo (DE BONI, 2000). A obra Polycraticus, a qual estudamos para este artigo, traz 
alguns apontamentos sobre a formação do príncipe, daquele que seria o responsável pela condução do bem-público.

Boaventura de Bagnoregio foi um eminente teólogo franciscano e mestre universitário do século XIII. Também estudou em Paris, mas numa época diferente da de João de Salsbury: enquanto este viveu um período de ascensão dos estudos superiores no Ocidente, Boaventura viveu o apogeu do pensamento escolástico e presenciou o nascimento da Universidade. $O$ texto que elegemos para fundamentar nosso debate, $A$ perfeição da vida, contém ensinamentos sobre o pensar e o agir dos religiosos mendicantes no século XIII. Contudo, vale ressaltar que o teólogo não trata de qualquer religioso, nem de qualquer mendicante, mas do mendicante franciscano, a fim de formá-lo para a liderança, para o ministério reservado a ele: direcionar os homens para os princípios da sociedade cristã.

Principiemos pelo Polycraticus, de João de Salsbury. Para abordar o caráter do príncipe, do governante, o autor parte de uma análise da sociedade, baseando seus argumentos em autores da Antiguidade clássica. Em primeiro lugar, esclarece que os homens vivem como se estivessem numa comédia, mas na realidade vivem uma tragédia. Demoramos a perceber a diferença entre comédia e tragédia porque fomos educados dessa maneira e ela, por seu turno, gera o hábito:

De fato, conheci crianças que imitaram por tanto tempo os balbucios que, depois, nem mesmo querendo, conseguiram falar corretamente. Como se costuma dizer, o hábito é esquecido com dificuldade, e o costume plasma uma outra natureza que, 'se a expulsares com o forcado, retorna por si sorrateiramente'. Por isso, é útil o conselho do poeta ético quando diz: 'Escolhe para ti desde criança o melhor modo de vida, e o hábito haverá de torna-lo agradável' (JOÃO DE SALSBURY, 2000, p. 138).

A citação acima é importante por evidenciar uma das características essenciais da educação: ela forma o hábito. É segundo o processo educativo, na perspectiva de João de Salsbury, que passamos a viver de um modo ou de outro. É assim que os homens se habituam a viver numa 'tragédia' como se fosse uma 'comédia'. 
Outro aspecto importante no texto de João de Salsbury e que nos permite refletir sobre a educação e a formação humana, na perspectiva histórica, é sua análise sobre o acaso:

Também o acaso - que é definido como um acontecimento fortuito - não existe, pois nada existe sem uma causa e uma razão precedente, e o pregador fiel ensina que nada acontece na terra sem um motivo (Jó 5,6$)$. Contudo, como não poucas coisas acontecem inesperadamente, para além da intenção de quem age, costuma-se coloca-las sob o acaso. Em verdade, porém, elas foram previstas por aquele que as dispôs segundo a razão, da mesma forma daqueles que parecem determinadas pela lei natural (JOÃO DE SALSBURY, 2000, p. 140).

Consideramos importante a afirmação do autor de que há nas ações humanas um princípio, 'uma causa e uma razão precedente'. Nessa perspectiva, atribuir ao acaso, à sorte, aquilo que recai na responsabilidade dos homens não pode ser considerado um ato legítimo, uma vez que o homem sempre age de acordo com princípios e visando um determinado fim. O PNE é, sobretudo, um projeto, a causa e a razão precedente da educação que almejamos para os próximos dez anos - daí a relevância de refletirmos sobre suas metas.

Se pensarmos o Plano Nacional como um projeto, precisamos considerar, também, as transformações que precisamos operar na sociedade para que ele se efetive. Contudo, vale questionar se os princípios nele estabelecidos estão em consonância com nossa intenção de promover a civilização - amadurecimento concomitante dos indivíduos e das instituições. João de Salsbury traz, nesse sentido, uma 'lembrança' fundamental:

Embora o local em que moramos esteja cercado por nove orbes, ou esferas, contudo, um dia deveremos dele sair, e o inexorável Caronte haverá de fazer que todos atravessem o rio com sua barca carregada de anos. Uns sucedem-se aos outros e assim, passando os 
indivíduos, permanece a espécie humana, do mesmo modo como, passando a água, a mesma corrente permanece no rio (JOÃO DE SALSBURY, 2000, p. 142).

Quando ressaltamos a questão da reflexão sobre se os princípios contidos no PNE são, de fato, pertinentes para o desenvolvimento da civilização, temos em mente essa ideia trazida pelo autor de que a 'espécie humana' permanece, ainda que os indivíduos sejam transitórios. Entendemos que essa afirmação nos ajuda a estabelecer algumas indagações a respeito das metas do PNE para a formação de professores, como: qual professor estamos formando? qual professor queremos formar? e, finalmente, qual professor precisamos formar?

O autor nos ensina que nossas ações devem ter como preocupação primeira a espécie humana, isto é, a conservação do que nos caracteriza como seres humanos, que entendemos ser fundamentalmente o conhecimento complexo (abstrato), a consciência e a liberdade. Se pensarmos dessa maneira, temos subsídios para começar a responder às perguntas feitas no parágrafo anterior. Com relação ao professor que estamos formando, se os dados provenientes das avaliações nacionais e internacionais demonstram, além do desempenho dos alunos, o desempenho dos professores, eles nos provam que os professores precisam de uma formação mais substancial que os capacite não somente para o domínio dos conhecimentos específicos de dada disciplina, mas também para o ato de ensinar, sem abrir mão dos fundamentos teóricos da educação - necessários para saber qual 'natureza' de homem queremos e devemos formar.

Em relação ao professor que queremos formar, o PNE se constitui como um documento importante, pois nos fornece princípios importantes que apontam para a formação docente na atualidade. $\mathrm{O}$ Plano Nacional de Educação que está em vigência é regulado pela lei $n^{\circ} 13.005$ de 25 de junho de 2014 e está dividido em duas partes: $\mathrm{Na}$ primeira, abordam-se as diretrizes para o cumprimento das 20 (vinte) metas que compõem a segunda parte, o anexo. Acreditamos que essas 20 (vinte) metas explicitam a educação que queremos no futuro, mais 
precisamente até 2024. Dessa forma, pode demonstrar ou não a sociedade que pretendemos ser. Acreditamos que a análise das questões estabelecidas acima pode ser parte da resposta a esse outro problema: se o nosso projeto de educação está vinculado à um projeto de sociedade.

Em primeiro lugar, vale ressaltar que o professor é chamado no PNE de profissional da educação, assim como os gestores e demais colaboradores que trabalham na escola. A meta 15 do PNE afirma que o Estado deve assegurar "[...] que todos os professores e as professoras da educação básica possuam formação específica de nível superior, obtida em curso de licenciatura na área de conhecimento em que atuam" (BRASIL, 2014, s./p.). Essa meta contém algumas estratégias, das quais 7 (sete) tratam diretamente da formação dos professores.

A primeira dessas estratégias, de número 15.2, prevê a consolidação do financiamento estudantil para que as pessoas procurem cursos de licenciatura na rede privada de ensino que sejam bem avaliados no Sistema Nacional de Avaliação da Educação Superior (SINAES). Ela assegura, ainda, a amortização da dívida nos casos em que os professores assumam "[...] docência efetiva na rede pública de educação básica" (BRASIL, 2014, s./p.).

A segunda estratégia, 15.3, proporciona a ampliação dos programas de iniciação à docência para que os estudantes dos cursos de licenciatura se aperfeiçoem em conhecimentos didáticos e pedagógi$\cos ^{1}$. Notamos, contudo, que não há no PNE uma tentativa de articular a pesquisa com o ensino, incentivando, por exemplo, os estudantes a participarem de programas de iniciação científica. Essa separação é, a nosso ver, negativa, pois entendemos, a partir da leitura dos clássicos que trouxemos para este artigo, que a união entre docência e pesquisa significa a articulação entre a teoria e a prática, entre o conhecimento

1 Dentre esses programas, destacamos o Programa Institucional de Bolsa de Iniciação à Docência (PIBID). Trata-se de uma iniciativa da Coordenação de Aperfeiçoamento de Pessoal de Nível Superior (CAPES) para promover a formação de alunos dos cursos de licenciatura. O objetivo principal é a inserção desses alunos na realidade escolar das escolas públicas, de modo que eles terminem a graduação mais bem preparados para o exercício da docência. 
e os processos de ensino e aprendizagem. Aliás, tanto João de Salsbury como Boaventura de Bagnoregio parecem afirmar a unicidade entre o pensamento e a ação, entre o que se conhece e o que se faz.

Outra estratégia que consideramos importante observar é a que trata da promoção de reformas curriculares dos cursos de licenciatura. A meta 15.6 afirma que essa reforma consiste no estabelecimento de matrizes curriculares que contemple

[...] formação geral, formação na área do saber e didática específica e incorporando as modernas tecnologias de informação e comunicação, em articulação com a base nacional comum dos currículos da educação básica [...] (BRASIL, 2014, s./p.).

Por ser um plano, não há detalhamento sobre como seria a formação geral, nem como seria a formação específica e como os cursos articulariam seus conteúdos com os da educação básica. Assim, cabe aos professores e gestores da educação superior a formação dessas matrizes curriculares de acordo com as demandas da sociedade.

Já a estratégia 15.12 é importante por tratar de um tema fundamental para a formação básica, o ensino de idiomas estrangeiros. Segundo o PNE, ao Estado cabe

[...] instituir programas de concessão de bolsas de estudos para que os professores de idiomas das escolas públicas de educação básica realizem estudos de imersão e aperfeiçoamento nos países que tenham como idioma nativo as línguas que lecionam (BRASIL, 2014, s./p.)

O PNE não estabelece, de imediato, as regras para esse processo. Entretanto, caberá ao Estado regular a concessão dessas bolsas. Acreditamos que um elemento deva ser a base para que essa estratégia se torne realidade, que é o mérito. Há que se fazer uma seleção se as bolsas não forem suficientes para todos, mas, principalmente, uma avaliação do desempenho do professor antes da imersão e do 
aperfeiçoamento e também depois, a fim de saber se houve algum impacto do trabalho efetivo dentro da sala de aula. Do contrário, há a possibilidade de desperdício de recursos em programas que não geram impactos significativos na aprendizagem dos alunos - fim último, na perspectiva dos autores clássicos, da educação.

Para a finalidade deste artigo, vale ressaltar, também, a meta 16 do PNE, que afirma ser necessário formar $50 \%$ dos professores da educação básica em nível de pós-graduação até o último ano de sua vigência. Além disso, a meta pretende que o Estado propicie formação continuada a todos os profissionais da educação, dentre eles o professor.

Essa meta 16 contém 6 (seis) estratégias. Duas delas precisam, no nosso julgamento, uma atenção especial, que são aquelas que tratam do incentivo à leitura e ao acesso a outros bens culturais (estratégias 16.3 e 16.6). Entendemos que elas mereçam uma análise mais detalhada, porque o professor, uma vez encarregado do ensino, já que é o responsável direto e imediato pela aprendizagem do aluno, é o leitor por excelência. $\mathrm{Na}$ medida em que o PNE precisa estabelecer estratégias para que os professores leiam e procurem acesso a outros bens culturais, significa que vivemos uma realidade de professores que não leem, isto é, que não estudam. Aliás, vale ressaltar que a necessidade da leitura e do aprimoramento, por meio de estudos avançados, não está implicada na condição de professor da educação básica pública, mas sim, na condição de ser professor. Dessa maneira, não haveria necessidade de o Estado adotar medidas para incentivar a leitura entre os professores se entendêssemos o hábito da leitura como pressuposto do ser professor.

Nesse momento, podemos avançar até a pergunta que consideramos crucial, que é a terceira: que professores precisamos formar? A conservação da espécie humana, na perspectiva de João de Salsbury, e o desenvolvimento da civilização, na de Guizot, depende sobremaneira da resposta que damos a essa questão. Contudo, não temos a pretensão de fornecer respostas definitivas para a formação de um professor 'perfeito', mas procuramos trazer dois pensadores clássicos da Idade Média 
por acreditarmos que esses autores souberam sintetizar as virtudes necessárias para a constituição de líderes - dentre os quais identificamos o professor.

Para nos auxiliar na reflexão sobre o professor que precisamos formar, recuperamos o texto escolhido de Boaventura de Bagnoregio, intitulado A perfeição da vida.

Em A perfeição da vida, o autor elenca os princípios que devem nortear a vida de uma irmã Clarissa, o braço feminino da Ordem Franciscana. Ainda no Prólogo, o teólogo afirma que a condição necessária para um religioso é ser bem-aventurado e esclarece o que entende por isso:

Bem-aventurado o homem a quem tu, Senhor, instruíres e amestrares na tua santa lei. Não tenho a ninguém por sábio, senão ao que é instruído pela unção do Espírito Santo. Porque, segundo o testemunho do profeta David, só é verdadeiramente bem-aventurado e verdadeiramente sábio aquele cuja mente o Senhor doutrinou, cujo coração amestrou em sua lei. O motivo é porque somente a lei do Senhor é imaculada, irrepreensível e somente ela converte as almas à salvação. [...] Comparada a seus ensinamentos, toda a sabedoria do mundo é estultice e loucura (SÃO BOAVENTURA, 1983, p. 407) ${ }^{2}$.

Conforme o excerto acima, o religioso bem-aventurado é aquele que é, sobretudo, bem instruído. Ser bem instruído, na perspectiva de Boaventura, frade franciscano do século XIII, significa conhecer as leis de Deus, os costumes cristãos e, também, agir de acordo com os preceitos conhecidos. Não há, ou não deve haver, uma separação entre o que se sabe e

2 Cabe ressaltar aqui que Boaventura de Bagnoregio, assim como João de Salsbury, viveram e produziram no contexto de desenvolvimento da Escolástica. O pensamento escolástico se caracteriza pela busca da conciliação entre razão e fé, duas naturezas distintas de conhecimento que se completam em torno de um fim comum, o amadurecimento pleno do homem como ser dotado de intelecto e vontade e como criação divina (OLIVEIRA, 2005). Não se trata tão-somente de um conjunto de ritos e crenças religiosas, e quando os autores escolásticos falam da bemaventurança e da salvação, procuram fundamentos tanto na Filosofia pagã como nas Sagradas Escrituras, buscando a compreensão total (ou totalizante) do homem e das relações sociais. 
o que se faz. O religioso, aquele que o autor entendia como responsável por estar à frente da comunidade cristã, deve ser, então, o primeiro a conhecer e a agir conforme a 'santa lei'.

Para tratar do conhecimento e da ação pertinente ao frade e à irmã franciscanos, o autor divide o texto em 8 (oito) capítulos. Em cada um deles trata de um aspecto da vida que os religiosos precisam cultivar, a fim de serem excelentes, isto é, o melhor dentre os melhores indivíduos da sociedade. No primeiro capítulo, Boaventura afirma que deve-se conhecer a si mesmo, e isto a partir da consideração de três elementos: a negligência, a concupiscência e a malícia. Sobre a negligência, ele escreve que

Portanto, se desejas conhecer-te a ti mesma e chorar os males cometidos, deves, primeiro, investigar se há ou houve em ti alguma negligência: se foste negligente na guarda do coração, no emprego do tempo e na direção das ações. Esse tríplice exame deve ser rigoroso, pois que cada um deve, sempre e com o máximo cuidado, guardar puro o seu coração, empregar utilmente o seu tempo, e dirigir todas as suas ações para o fim devido (SÃO BOAVENTURA, 1983, p. 408).

Como podemos observar na passagem citada, para investigar se é negligente, deve-se verificar se o coração é puro, se o tempo é empregado de maneira útil e se as ações são bem direcionadas. Destacamos, para a finalidade deste artigo, os dois últimos elementos. O religioso, na perspectiva do autor, deve utilizar o tempo à disposição para ações úteis, ao mesmo tempo em que essas ações devem estar direcionadas ao fim devido. Para ele, parece evidente que a utilidade do tempo e a pertinência das ações estão relacionadas à salvação e ao alcance da vida eterna. Porém, como se trata daqueles que não devem se preocupar somente com a própria salvação, mas também com a salvação dos demais cristãos, o tempo e as ações devem ser condicionados para o bem-comum, além do bem individual.

Em segundo lugar, Boaventura defende que conhecer-se a si mesmo passa, também, pela consideração da concupiscência, isto é, se o religioso(a) domina a concupiscência da voluptuosidade, da curiosidade e da vaidade: 
Com certeza, reina no religioso a concupiscência da voluptuosidade quando deseja o que é delicado, o que é deleitoso e o que é carnal, isto é, quando deseja vestuários graciosos, alimentos saborosos, prazeres luxuriosos. - A concupiscência da curiosidade se manifesta na serva de Deus, quando deseja saber o que é secreto, ver o que é formoso, possuir o que é raro. - A concupiscência da vaidade impera na esposa de Cristo quando deseja receber favores, elogios ou honrarias humanas. - De tudo isso deve fugir a serva de Deus como de um veneno, porque nisso se enraízam todos os males (SÃO BOAVENTURA, 1983, p. 409).

Segundo os princípios mencionados, vale destacar que Boaventura de Bagnoregio vive um contexto de transformações e conflitos em torno do surgimento das ordens religiosas. A forma de vida dos frades e irmãs das diversas ordens mendicantes que surgiram no século XIII suscitou uma série de debates sobre o comportamento de outras pessoas do clero, principalmente relacionados ao acúmulo de riquezas e de poder (LE GOFF, 2008). Além disso, observamos, em particular, o que apresenta sobre a vaidade. Para ele, o religioso não deve procurar elogios e honrarias por fazer o que é sua função própria. Entendemos que o teólogo não se refere ao reconhecimento do papel dos frades, mas sim, às benesses desproporcionais em relação à ação dos frades e irmãs que poderiam conduzi-los a um estado de espírito incoerente com seus propósitos ${ }^{3}$.

A terceira condição para que o religioso conheça a si mesmo é considerar se se é malicioso:

Em terceiro lugar, para te conheceres perfeitamente, examina-te com solicitude se sentes ou já sentiste em ti as emoções más da cólera, da inveja, da acédia. - Pois ouve o que te digo: No homem religioso existe a cólera quando no espírito, no coração, no afeto, nos gestos, no rosto, na palavra ou na voz revela ao seu próximo a indignação do coração, por mais leve que seja, ou o rancor. - A inveja reina no homem quando

3 Sobre essa questão, consideramos relevante pontuar um dado importante. Já no século XIII há, entre os mendicantes, registros de pessoas e igrejas que vivem de maneira suntuosa. Nesse sentido, acreditamos que o autor esteja respondendo, também, ao comportamento de alguns religiosos de sua própria ordem. 
se regozija pelo infortúnio do próximo e se entristece pela sua prosperidade, quando se alegra com os males dos seus semelhantes e desfalece com a sua felicidade. - A acédia reina no religioso quando é tíbio, sonolento, ocioso, lerdo, negligente, frouxo, dissoluto, indevoto, triste e tedioso. Todas essas maldades deve detestá-las a esposa de Cristo e fugir-lhes como de peçonha mortífera, pois que delas provém a perdição do corpo e da alma (SÃO BOAVENTURA, 1983, p. 409).

Observamos, na passagem apresentada, que os frades e as irmãs franciscanos, aqueles que devem cuidar de sua própria salvação, mas sobretudo, dos demais cristãos, devem desenvolver o hábito da serenidade. Não se deve alimentar a ira de maneira desmedida, nem a inveja e nem a preguiça, pois significam a porta de entrada para os vícios e o cerceamento das virtudes necessárias para a formação do líder. Destacamos aqui, principalmente, as questões da inveja e da 'acédia', uma vez que a inveja, ao impelir o homem a sentir tristeza pelo sucesso alheio, conduz à desconsideração da possibilidade da salvação do outro, algo impensável para os frades e as irmãs; e a 'acédia', ao provocar a inação pela preguiça, obstaculiza a ação evangelizadora, objetivo próprio do religioso mendicante.

Depois de tratar do conhecimento de si mesmo, passa Boaventura a abordar os elementos condicionantes para o desenvolvimento das virtudes. Começa pela necessidade de se ter humildade, afirmando que ser humilde significa negar a soberba e dedicar-se ao aprimoramento do outro de maneira franca e autêntica: "A humildade, pois, é uma virtude tão imprescindível que sem ela não somente não há virtude, mas ainda a própria virtude se adultera em soberba" (SÃO BOAVENTURA, 1983, p. 412). Nesse sentido, Boaventura afirma que a humildade só pode ser percebida na totalidade do ser, isto é, não basta que o religioso seja humildade ao falar, ou ao andar, mas é necessário que a essa virtude perpasse todas as ações do sujeito: "Aprendei, portanto, virgens consagradas, a terdes um espírito humilde, um andar humilde, sentidos humildes, vestidos humildes,

4 A palavra 'acédia' significa 'estado de grande melancolia'. A palavra que é aplicada mais comumente para referir-se à essa ideia é 'acídia'. Entretanto, como na tradução que lemos do texto de Boaventura a palavra que aparece é 'acédia, optamos por mantê-la. 
pois que exclusivamente a humildade mitiga a ira divina e encontra graça diante de Deus" (SÃO BOAVENTURA, 1983, p. 413).

Além da humildade, o autor afirma ser necessário para os religiosos franciscanos a qualidade do silêncio. Nesse aspecto, podemos perceber que o silêncio é condição, também, para ser instruído e humilde, duas das virtudes que destacamos do texto do teólogo:

Se o homem não põe com muito cuidado uma guarda à sua boca, não só dissipará bem cedo as graças que recebeu, mas incorrerá ainda em muitos males. A língua é um pequeno membro, diz são Tiago em sua epístola, mas gloria-se de grandes coisas. Vede como um pouco de fogo incendeia um grande bosque. Também a língua é um fogo, um mundo de iniquidade; ela está cheia de veneno mortífero. <<É pela língua, acrescenta a Glosa, que são combinados e cometidos quase todos os crimes > >. Queres ouvir e saber quantos males produz a língua, quando não é guardada solicitamente? Pois ouve: a língua produz a blasfêmia, a murmuração, a defesa do pecado, o perjúrio, a mentira, a detração, a adulação, as pragas, as injúrias, as rixas, a ridicularização dos bens, os maus conselhos, a difamação, a jactância, a revelação dos segredos, as ameaças e promessas arrogantes, o excesso no falar, a chocarrice. (SÃO BOAVENTURA, 1983, p. 420).

Apesar de Boaventura destacar, na passagem acima, todos os defeitos de falar demasiadamente, ele pontua, também, a necessidade de romper o silêncio. Aliás, não podemos esquecer que o religioso, para ensinar, deve falar e escrever, pois a palavra é o pressuposto da ação de evangelização. É preciso, portanto, que o religioso tenha conhecimento e prudência para que exerça sua liderança de maneira virtuosa, para que cumpra sua finalidade a qual já destacamos neste artigo - preocupar-se com a formação e a salvação dos cristãos:

Fala, portanto, raras vezes, pouco e brevemente. Fala com temor e pudor. Ainda mais: fala com dificuldade no que te diz respeito. Cobre a tua face com o véu da modéstia. Cose os teus lábios com o fio da disciplina. O teu falar seja breve, precioso e útil, modesto e humilde. (SÃO BOAVENTURA, 1983, p. 422). 
Outro elemento que consideramos importante no texto de Boaventura de Bagnoregio e que nos permite refletir sobre a ação docente é a importância da memória para o religioso franciscano. No Capítulo VI d'A perfeição da vida, o autor aborda a necessidade de se lembrar sempre da paixão de Cristo. Ele afirma que a lembrança constante da paixão de Cristo faz com que o frade e a irmã conservem em si o fervor e a devoção, princípios necessários para balizar suas ações entre os homens. Aqui, a memória se coloca não somente como uma qualidade do indivíduo que figura ao lado do intelecto e da vontade, mas também como a possibilidade de preservação da tradição cristã, por meio da qual todo cristão deve ser formado. Assim, as ações da liderança religiosa, que Boaventura acredita poder ser exercida pelos Franciscanos, devem partir da memória para conservar as instituições necessárias para o desenvolvimento da civilização.

Por fim, destacamos da obra em questão a virtude da perseverança. Além de conhecer a si mesmo, de cultivar a humildade, o silêncio e a memória, o autor enfatiza a importância de o religioso manter-se firme em seu propósito de salvação, de si mesmo e dos outros:

Nenhum mortal, por mais perfeito que seja, é digno de louvor durante a sua vida, enquanto não tiver concluído com um bom e feliz êxito o bem que começou. Porque a perseverança é o fim e <<a consumadora das virtudes, a nutridora dos méritos e a medianeira do prêmio >> (SÃO BOAVENTURA, 1983, p. 435).

E a perseverança, para além de uma atitude que reforça a beatitude do ato, contribui para que o sujeito tenha, também, coerência, isto é, perseverar na bondade faz com que sejamos bons como um todo, não apenas em determinados atos particulares:

Se possuis, pois, alguma habilidade em boas obras, ou antes justamente por possuíres muitas virtudes, persevera nelas, progride e com ânimo varonil exerce nelas a milícia de Cristo até a morte, para que, quando chegar o último dia e o fim da tua vida, recebas em recompensa o prêmio de teus labores, a coroa da honra e da glória. (SÃO BOAVENTURA, 1983, p. 436). 
Nessa perspectiva, o frade e a irmã franciscanos devem manter a motivação para aquilo que é o fim último de suas ações entre os homens. Isso significa que a salvação, de si e dos outros, deve ser perseguida com a mesma dedicação ao logo da vida, de modo que o arrefecimento da vontade de cumprir seus objetivos o descaracteriza como líder religioso, como responsável pela comunidade cristã.

Acreditamos que essa obra de Boaventura de Bagnoregio nos traz algumas lições sobre a formação e constituição de professores, pois destaca as virtudes necessárias às pessoas que, no século XIII, tinham a incumbência de ensinar e formar no outro, o hábito de acordo com as demandas e necessidades daquela sociedade. Entendemos que, atualmente, os professores formam um dos principais grupos responsáveis pela formação dos indivíduos. As decisões e ações que tomamos em relação à escola geram impactos positivos ou negativos, a depender de nossas preocupações em relação à nossa formação e à aprendizagem dos alunos. Da mesma forma que o religioso, no século XIII, precisa perseguir não somente o bem, mas a excelência para poder ensinar, o professor do século XXI também precisa se preocupar em ser, para os alunos e a sociedade, a referência essencial para a obtenção do conhecimento e a formação de cidadãos, capazes de continuar aprendendo e usufruir, com consciência, da liberdade que lhes garante a lei e o estado democrático de direito.

\section{Considerações finais}

Face às reflexões que apontamos no decorrer do texto, gostaríamos de observar alguns aspectos que consideramos essenciais a guisa de finalização. Em primeiro lugar, salientamos a importância e a necessidade de a História da Educação, e mais particularmente a História da Educação na Idade Média, fazer parte da formação dos futuros professores. Não nos posicionamos dessa maneira para defender, aqui, um corporativismo obtuso, mas ressaltar a relevância da leitura dos clássicos medievais para a formação dos educadores - da mesma forma como defenderíamos, 
em ocasiões diferentes, mas semelhantes, a leitura de textos clássicos da História, da Filosofia, da Sociologia e de outras áreas das Ciências Humanas e Sociais. Entendemos que o estudo desses pensadores nos auxilia a tirar lições importantes sobre os homens e as relações sociais.

Em segundo lugar, destacamos o debate sobre o Plano Nacional de Educação. Esse documento deve, a nosso ver, fazer parte das preocupações de professores e pesquisadores, uma vez que ele servirá, daqui para frente, de base para a condução da educação brasileira e deverá nortear os Projetos Políticos Pedagógicos nos diferentes níveis de ensino. Sobre isso, gostaríamos de salientar que, por ser um Plano, ele estabelece diretrizes e metas mínimas para o desenvolvimento educacional do país, cabendo a nós, professores, estudiosos e gestores da educação, a função de executar, não só o que o Plano instituí como metas mínimas, mas agir de maneira a buscar a excelência. É justamente, nesse aspecto que compreendemos a importância dos clássicos para a formação docente e a análise das questões educacionais do presente, pois eles nos permitem refletir sobre o significado de uma educação excelente, sobre o que é o homem e sobre o que seja a sociedade.

Assim, retomamos os conceitos de civilização de Guizot e de História de Nietzsche, pois, ao recuperar os clássicos para compreender o Plano Nacional de Educação procuramos entender, por um lado, quais as perspectivas que se apresentam atualmente para o amadurecimento dos indivíduos e das relações sociais e, por outro, buscamos fazer uso profícuo da História na tentativa de 'dar vida' às obras que não estudamos com frequência, mas que nos ensinam sobre temas importantes, notadamente sobre a formação docente.

\section{Referências}

BLOCH, M. L. B. Apologia da história, ou, O ofício de historiador. Rio de Janeiro: Jorge Zahar , 2001. 
BRASIL. Lei $\mathrm{n}^{\circ}$ 13.005, de 25 de junho de 2014. Aprova o Plano Nacional de educação - PNE e dá outras providências. Disponível em: <http://www.planalto.gov.br/ CCIVIL_03/_Ato2011-2014/2014/Lei/L13005.htm>. Acesso em 30 out. 2014.

GILSON, E. A filosofia na Idade Média. São Paulo: Martins Fontes, 1995.

GUIZOT, F. História da Civilização na Europa. Lisboa: Livraria, Editora, Officinas Typographicas e de Encadernação, 1907.

JOÃO DE SALSBURY. Polycraticus. In: DE BONI, L. A. de. Filosofia Medieval: textos. Porto Alegre: EDIPUCRS, 2000. p. 137-146.

LE GOFF, J. Uma longa Idade Média. Rio de Janeiro: Civilização Brasileira, 2008.

LE GOFF, J. Os intelectuais na Idade Média. Rio de Janeiro: José Olympio, 2010.

NIETZSCHE, F. W. Segunda consideração intempestiva: da utilidade e desvantagens da história para a vida. Rio de Janeiro: Relume Dumará, 2003. (Conexões; 20).

OLIVEIRA, T. Guizot e a Idade Média: civilização e lutas políticas. 1997. Tese (Doutorado em História) - Unesp, Assis, 1997.

OLIVEIRA, T. Escolástica. São Paulo: Mandruvá, 2005.

SÃO BOAVENTURA. A perfeição da vida. In: . Obras escolhidas. Porto Alegre: Escola Superior de Teologia São Lourenço de Brindes, Liv. Sulina; Caxias do Sul: Editora da Universidade de Caxias do Sul, 1983.

Recebido: 20/07/2015

Received: 07/20/2015

Aprovado: 17/11/2015

Approved: $11 / 17 / 2015$ 
